\title{
Trastuzumab in the Treatment of Breast Cancer - New Developments
}

\author{
Christian Jackischa Michael Untch ${ }^{\mathrm{b}}$ \\ a Klinik für Gynäkologie und Geburtshilfe und Brustzentrum Klinikum Offenbach GmbH, \\ ${ }^{\mathrm{b}}$ Frauenklinik/Interdisziplinäres Brustzentrum, Helios Klinikum Berlin-Buch, Akademisches LK der Universität Charité, Berlin, Germany
}

\section{Key Words}

Trastuzumab - Breast cancer - Adjuvant setting - Breast cancer, metastatic $\cdot$ HER-2/neu

\section{Summary}

Rarely a new drug has influenced the current concept of up-to-date systemic treatment in breast cancer like trastuzumab since the identification of the human epidermal growth factor receptor 2 and its implementation as strong prognostic as well as predictive factor. In human breast cancer, amplification of the HER-2/neu gene results in protein overexpression and poor prognosis. Patients whose tumors have HER-2/neu gene amplification have a shorter disease-free survival time than patients whose tumors exhibit a normal HER-2/neu gene copy number. HER-2/neu gene amplification identifies a biologically unique subset of aggressive breast tumors that are sensitive to growth inhibition and apoptosis induced by anti-HER-2/neu-targeted therapies. Trastuzumab therapy prolongs the survival of patients with metastatic HER-2/neu-overexpressing breast cancer when combined with chemotherapy and has recently been demonstrated to lead to dramatic improvements in disease-free survival when used in the adjuvant therapy setting in combination with or following chemotherapy. Most recent findings are suggesting that trastuzumab might be used in combination with chemotherapy as well as in combination with endocrine treatments, limited to patients presenting with metastatic disease. Still under debate are methods of proper HER-2/neu testing, patient selection, cardiotoxicity, duration of therapy, and directions for future research.

\section{Schlüsselwörter}

Trastuzumab - Mammakarzinom - Adjuvante Therapie · Mammakarzinom, metastasiertes · HER-2/neu

\section{Zusammenfassung}

Kaum eine andere Substanz hat wie Trastuzumab die aktuelle Entwicklung der Systemtherapie des Mammakarzinoms beeinflusst, seitdem der humane epidermale Wachstumsfaktorrezeptor-2 identifiziert und seine prognostische und prädiktive Bedeutung evaluiert wurde. Die Amplifikation des HER-2/neu-Gens führt zu einer Proteinüberexpression mit schlechter Prognose. Patientinnen, deren Tumoren eine Amplifikation des HER-2/neu-Gens aufweisen, haben ein kürzeres krankheitsfreies Intervall sowie ein kürzeres Überleben als Patientinnen, deren Tumoren einen diploiden Chromosomensatz aufweisen. Die Amplifikation des HER-2/neu-Gens identifiziert ein biologisch einmaliges Subkollektiv aggressiver Mammakarzinome, die auf anti-HER-2/neu-gerichtete Therapien mit Wachstumsinhibition und Apoptose reagieren. Trastuzumab gestützte Therapieformen führen zu einer Überlebensverlängerung beim metastasierten Mammakarzinom und, wie kürzlich berichtet, auch zu einer deutlichen Verlängerung des krankheitsfreien Überlebens, wenn Trastuzumab in der adjuvanten Situation, konkomittierend oder sequentiell mit einer Chemotherapie, eingesetzt wird. Aktuell publizierte Daten lassen den Einsatz von Trastuzumab auch in Kombination mit einer antihormonellen Therapie beim metastasierten Mammakarzinom als sinnvoll erscheinen. Die Optimierung der validen HER-2/neuTestung, die optimale Patientinnenselektion, aber auch die Bedeutung der Kardiotoxizität und die optimale Dauer der Therapie sind - gemeinsam mit der weiteren Entwicklung von therapeutischen Anwendungen des monoklonalen Antikörpers - Gegenstand der klinischen Forschung.

\begin{tabular}{ll}
\hline KARGER & ( ) 2007 S. Karger GmbH, Freiburg \\
$\begin{array}{l}\text { Fax +49 7614520714 } \\
\begin{array}{l}\text { E-mail Information@Karger.de } \\
\text { www.karger.com }\end{array}\end{array}$ & $\begin{array}{l}\text { Accessible online at: } \\
\text { www.karger.com/brc }\end{array}$ \\
&
\end{tabular}

Prof. Dr. med. Christian Jackisch

Klinik für Gynäkologie und Geburtshilfe und Brustzentrum Klinikum Offenbach GmbH

Starkenburgring 66, 63069 Offenbach, Germany

Tel. +49 69 8405-3850, Fax -4456

E-mail christian.jackisch@klinikum-offenbach.de 


\section{Introduction}

Approximately $20-25 \%$ of all primary breast cancers reveal an overexpression of the human epidermal growth factor HER$2 /$ neu, a transmembraneous tyrosine kinase receptor, which is part of the HER family of receptors. HER-2/neu overexpression is associated with decreased disease-free and overall survival [1], indicating a key role of HER-2/neu in breast cancer pathogenesis and progression. The fact that trastuzumab given in metastatic breast cancer (MBC) leads to improved survival was regarded as a therapeutic revolution and the introduction of the era of targeted treatment in breast cancer. Based on these findings most of the clinical trials in all breast cancer settings, namely in the adjuvant and neoadjuvant setting, evaluated the incorporation of the human antibody in current or newly created therapeutic approaches. Thus, it was not a surprising observation that the speed of implementation of targeted treatments introducing trastuzumab was criticized as 'insufficient to make reliable judgments' by a leading international medical journal [2]. Until today trastuzumab has been implemented in all levels of breast cancer treatment, e.g. neoadjuvant, adjuvant as well as in the metastatic setting.

\section{Recommended Assessment of HER-2/neu Overexpression}

Early studies suggested that as many as $30 \%$ of breast cancers have HER-2 overexpression [3]. The frequency of HER2/neu-positive breast cancer appears to be lower when considering all patients with a new diagnosis of invasive breast cancer. Yaziji et al. recently reported their experience with large volume testing and observed that $18 \%$ of samples tested $(\mathrm{n}=$ 2,913 ) showed gene amplification by fluorescent in situ hybridization: FISH, defined as a HER-2:CEP17 ratio > 2) [4]. Others observed a frequency of HER-2/neu overexpression of $20 \%$ among 116,736 specimens tested by immunohistochemistry (IHC) and $22.7 \%$ among 6,556 specimens tested by FISH [5]. The American Society of Clinical Oncology (ASCO) Tumor Marker Guidelines Panel has recommended routine testing of HER-2/neu on newly diagnosed and metastatic breast cancer since 2001 [6]. Following these recommendations HER-2/neu testing should be routinely performed in patients with a new diagnosis of invasive breast cancer (table 1).

\section{Randomized Trials Adding Trastuzumab in the Adjuvant Setting}

The findings of the 4 major randomized clinical trials involving more than 13,000 high-risk women with HER-2/neu-overexpressing breast cancer using trastuzumab for 52 weeks with or in sequence to chemotherapy were demonstrating a decrease of early risk of recurrence by $50 \%$. More interestingly,
Table 1. Algorithm defining positive values for both HER-2 protein expression and gene amplification [6]

\begin{tabular}{ll}
\hline IHC & uniformal, intense membrane staining $>30 \%$ of tumor cells \\
FISH & $>6$ HER-2 gene copies per nucleus \\
FISH ratio & $\begin{array}{l}\text { HER-2 gene signals to chromosome } 17 \text { signals of more } \\
\text { than } 2.2\end{array}$ \\
\hline
\end{tabular}

IHC = Immunohistochemistry;

$\mathrm{FISH}=$ fluorescent in situ hybridization.

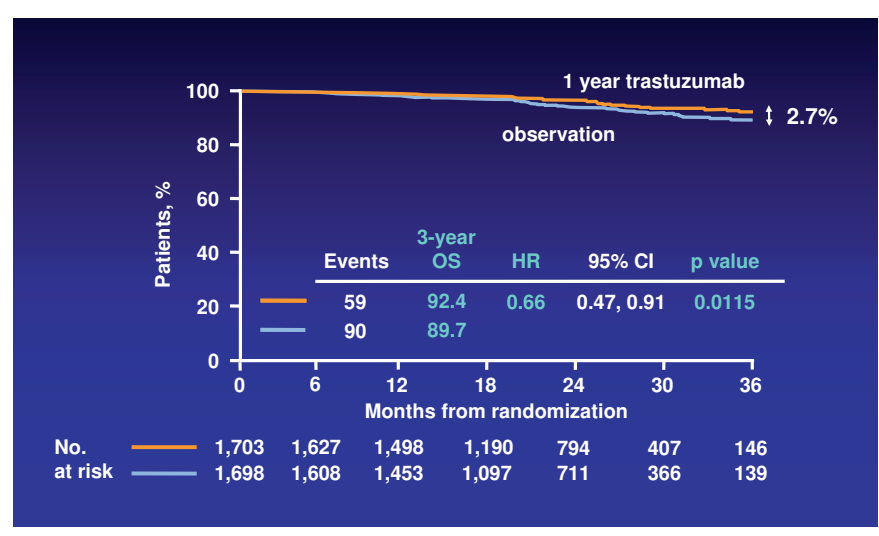

Fig. 1. Kaplan-Meier estimates of overall survival for 1 year of trastuzumab vs observation with a median follow-up of 2 years [8]; OS = Overall survival; $\mathrm{HR}=$ hazard ratio.

adding 1 year of trastuzumab in node-positive breast cancer resulted in an absolute survival rate at 3 years of $94.3 \%$ in the trastuzumab group and $91.7 \%$ in the control group (absolute difference: 2.5 percentage points; $95 \%$ confidence interval, CI: 0.1-5.0 percentage points); at 4 years, the respective rates were $86.6 \%$ and $91.4 \%$ (absolute difference: 4.8 percentage points; 95\% CI: $0.6-9.0$ percentage points) [7]. The recent findings of the 2-year follow-up on the HERA trial demonstrated an unadjusted hazard ratio (HR) for the risk of death in the trastuzumab group compared with observation alone of 0.66 (95\% CI: $0.47-0.91 ; \mathrm{p}=0.0115$ by the log rank test), which corresponds with an absolute overall survival benefit of $2.7 \%(92.4 \%$ vs $89.7 \%)$ at 3 years. The HR for overall survival by censored analysis was 0.66 (95\% CI: $0.45-0.87$; $\mathrm{p}=0.0051$ ) (fig. 1) [8].

\section{BCIRG 006: Results of the Second Planned Interim Analysis}

The BCIRG 006 study was designed to maximize efficacy while minimizing toxicity in adjuvant trastuzumab-based therapies. Between April 2001 and March 2004, the study enrolled 3,222 women with early stage HER-2-positive breast cancer, with positive axillary lymph nodes (LN) as well as those without $\mathrm{LN}$ involvement (fig. 2). In the second interim 


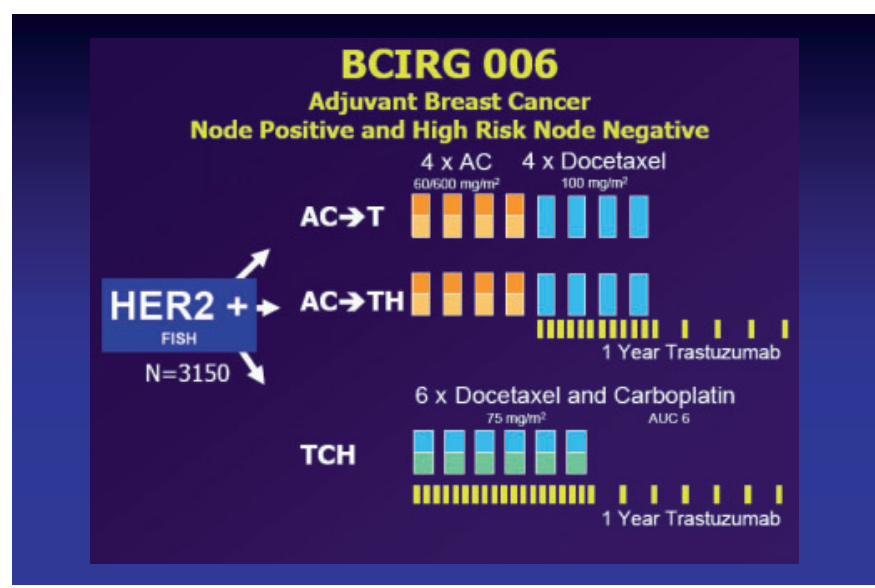

Fig. 2. $B C I R G-$ trial design.

analysis, at a 3-year median follow-up, AC-TH and TCH significantly improved disease-free survival (DFS) and overall survival (OS) as compared to the control arm [9]. The relative reduction in the risk of relapse was 39\% $(\mathrm{p}<0.001)$ and $33 \%$ ( $\mathrm{p}=0.0003$ ) respectively, for AC-TH and TCH vs control. The relative reduction in the risk of death was $41 \%$ ( $p<$ $0.0041)$ and $34 \%(\mathrm{p}<0.017)$ respectively, for $\mathrm{AC}-\mathrm{TH}$ and TCH vs control.

In addition, the absolute DFS benefit at 4 years is similar for the two trastuzumab-containing arms (6\% and 5\% for AC-TH and $\mathrm{TCH}$, respectively). Notably, the same level of DFS and OS benefit was also obtained for the $29 \%$ of node-negative patients enrolled in the study. In terms of safety, there was a significant difference in the major toxicity that has been consistently seen with trastuzumab-based therapies, i.e. cardiac toxicity.

Common to all adjuvant trials introducing trastuzumab was the evaluation of congestive heart failure and cardiac-related deaths. As mentioned above, the cardiac toxicity of the 2 experimental arms significantly favored the TCH regimen. No cardiac deaths were observed in either arm. There were 20 congestive heart failure events in the AC-TH arm versus 4 in the $\mathrm{TCH}$ arm. Moreover, there were 50\% fewer asymptomatic declines in cardiac function in the $\mathrm{TCH}$ arm as compared to AC-TH.

Further, in terms of other toxicities, the TCH regimen appeared to also be more favorable than the AC-TH regimen.

\section{Impact of Topoisomerase-II-alpha (topo-II- $\alpha$ )}

An unplanned retrospective subgroup analysis of coamplification of topo-II- $\alpha$ and HER-2/neu was done in 2,120 patients from the BCIRG-006 trial and suggested that the incremental benefit of AC-TH over TCH was confined to patients with coamplification of HER-2/neu and topo-II- $\alpha$, which is located in the same amplicon as HER-2/neu on chromosome 17q and is one of the targets of anthracycline chemotherapy [10].
Coamplification of the topo-II- $\alpha$ gene occurred in approximately $35 \%$ of HER-2/neu-positive patients and seemed to confer a therapeutic advantage to anthracycline/trastuzumabbased combination regimens. Patients with HER-2/neu-positive tumors that did not have coamplification of topo-II- $\alpha$, either deletion (4\%) or no amplification $(60 \%)$, did not receive the same benefit, and such patients might be candidates for efficacious, nonanthracycline-based regimens, avoiding potential cardiac toxicity. The most recent update of the BCIRG 006 trial failed to show the previous finding of such benefit, furthermore this target was not predictive for selecting one of the given chemotherapy regimens [9]. Thus, up to date there is no need for the routine assessment of topo-II- $\alpha$ as predictive marker in the adjuvant setting. This remains an interesting exploratory finding, but further confirmatory data are needed before any treatment guidelines can be recommended based on topo-II- $\alpha$ amplification.

\section{Optimal Duration of Trastuzumab in the Adjuvant Setting}

Despite the availability of the results of all major adjuvant trials the optimal duration of trastuzumab exposure remains unclear. The suspected duration of one year exposure to trastuzumab, as used in the majority of trials, was seriously challenged by the release of the FinHer trial [11]. This trial showed a significant advantage to the use of trastuzumab for only 9 weeks in the adjuvant therapy setting (in combination with docetaxel or vinorelbine). The study involved 1,010 patients randomized to docetaxel every 3 weeks for 3 doses versus 9 weeks of vinorelbine followed, in both groups, by three 3-week cycles of cyclophosphamide, epirubicin, and 5-fluorouracil (CEF). The 232 patients found to have HER-2/neupositive breast cancer by FISH were randomized to receive weekly trastuzumab for 9 weeks alone with docetaxel and vinorelbine. At a median follow-up of 3 years, adjuvant trastuzumab was effective in preventing breast cancer recurrences (HR: $0.46 ; p=0.0078$ ). In the group of patients assigned to trastuzumab treatment, the left ventricular ejection fraction (LVEF) was measured by either echocardiography or radionuclide ventriculography using multi-gated acquisition (MUGA) scan before chemotherapy, after the last CEF cycle, and 12 and 36 months after chemotherapy. One patient had cardiac infarction and 3 had cardiac failure; none of these 4 patients had received trastuzumab. LVEF was preserved in women who received trastuzumab. Four women treated with trastuzumab $(3.5 \%)$ and 7 who were not $(6.0 \%)$ had one or more LVEF measurements $>15 \%$ lower than the pretreatment value. A $>10 \%$ decrease, resulting in an LVEF of $<50 \%$, occurred in 3 patients, none of whom had received trastuzum$\mathrm{ab}$.

These findings challenged for the first time the optimal duration of trastuzumab exposure, while the HERA trial is still 


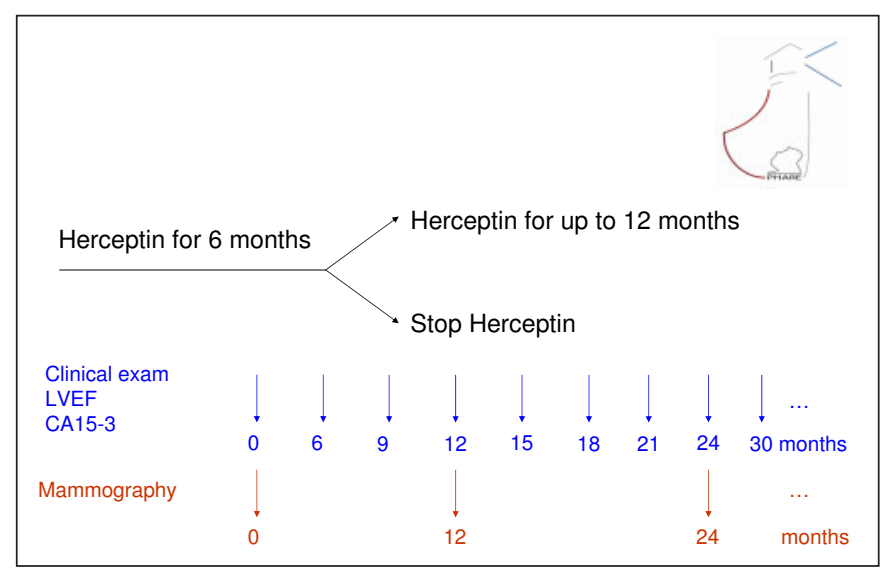

Fig. 3. $P H A R E-$ trial design $(n=7,000)$.

under investigation for the efficacy data of the two-year treatment with trastuzumab.

Optimal duration of exposure to trastuzumab remains unknown so far. Moreover it has been shown that the risk for cardiotoxicity is increased in patients treated with trastuzum$\mathrm{ab}$, particularly in those who have received an adjuvant chemotherapy containing an anthracycline [7-9, 11, 12]. In this context, French Institut National du Cancer (INCa) proposes a randomized clinical trial aimed at evaluating the non-inferiority, in terms of disease-free survival and cardiotoxicity, of a reduction of exposure to trastuzumab comparing 6 months versus 12 months after stratification by the mode of administration of chemotherapy (concomitant or sequential). This trial aims at being pragmatic, including a very large number of patients, with a follow-up as close as possible to that of routine clinical practice. The objective is to include all patients receiving an adjuvant treatment with trastuzumab in order to recruit 7,000 patients as soon as possible, within an 18-month inclusion period (fig. 3) [13].

In summary the following statements can be made:

1. Adjuvant trastuzumab treatment for 1 year in HER-2/neu overexpressing breast cancer patients in addition to chemotherapy can significantly improve disease free and overall survival.

2. This benefit is seen in node positive and node negative disease.

3. Open questions are longer versus shorter duration of treatment, anthracycline free adjuvant chemotherapy, duration of treatment and long term outcome.

\section{References}

1 Slamon DJ, Godolphin W, Jones LA, Holt JA, Wong SG, Keith DE, Levin WJ, Stuart SG, Udove J, Ullrich A: Studies of the HER-2/neu proto-oncogene in human breast and ovarian cancer. Science 1989;244:707-712.

$\checkmark 2$ Horton R: Herceptin and early breast cancer: a moment for caution. Lancet 2005;366:1673.

3 Slamon DJ, Clark GM, Wong SG, et al.: Human breast cancer: correlation of relapse and survival with amplification of the HER-2/neu oncogene. Science 1987;235:177-182.

4 Yaziji H, Goldstein LC, Barry TS, et al.: HER-2 testing in breast cancer using parallel tissue-based methods. JAMA 2004;291:1972-1977.

$\checkmark 5$ Owens MA, Horten BC, Da Silva MM: HER2 amplification ratios by fluorescence in situ hybridization and correlation with immunohistochemistry in a cohort of 6,556 breast cancer tissues. Clin Breast Cancer 2004;5:63-69.

6 Wolff AE, Hammond EH, Schwartz JN, et al.: American Society of Clinical Oncology/College of American Pathologists guideline recommendations for human epidermal growth factor receptor 2 testing in breast cancer. J Clin Oncol 2007;25: 118-148.

7 Romond EH, Perez EA, Bryant J, Suman VJ, Geyer CE, Davidson NE, Tan-Chiu E, Martino S Paik S, Kaufman PA, Swain SM, Pisansky TM, Fehrenbacher L, Kutteh LA, Vogel VG, Visscher DW, Yothers G, Jenkins RB, Brown AM, Dakhil SR, Mamounas EP, Lingle WL, Klein PM, Ingle JN, Wolmark N: Trastuzumab plus adjuvant chemotherapy for operable HER2-positive breast cancer. N Engl J Med 2005;353:1673-1684.
8 Smith I, Procter M, Gelber RD, Guillaume S, Feyereislova A, Dowsett M, Goldhirsch A, Untch M, Mariani G, Baselga J, Kaufmann M, Cameron D, Bell R, Bergh J, Coleman R, Wardley A, Harbeck N, Lopez RI, Mallmann P, Gelmon K, Wilcken N, Wist E, Rovira PD, Piccart-Gebhart MJ, for the HERA study team: 2-year follow-up of trastuzumab after adjuvant chemotherapy in HER2positive breast cancer: a randomised controlled trial. Lancet 2007;369:29-36.

9 Slamon D, Eiermann W, Robert N, Pienkowski P, Martin M, Pawliki M, Chan A, Smylie M, Liu M, Falkson C, Pinter T, Fornander T, Shiftan T, Valero V, von Minkwitz G, Mackey J, Tabah-Fisch I, Buyse M, Lindsay MA, Riva A, Bee V, Pegram M, Press $\mathrm{M}$, Crown J, on behalf of the BCIRG 006 Investigators: Phase III trial comparing AC-T with AC-TH and with $\mathrm{TCH}$ in the adjuvant treatment of Her2 positive early breast cancer patients: second interims efficacy analysis. Breast Cancer Res Treat 2006;100(suppl I):abstr 52.

10 Slamon D, Eiermann W, Robert N, et al.: Phase III trial comparing ACT with AC-TH and with $\mathrm{TCH}$ in the adjuvant treatment of HER2 positive early breast cancer patients: first interim efficacy analysis. Presented at the 2005 San Antonio Breast Cancer Symposium, San Antonio, TX. http://www. sabcs.org/

http://www.bcirg.org/NR/rdonlyres/eoslo3s4uykn6fo iyf2ps4zt52tp6odgwpivoaglnp7jntznfjfby23m547jrjryaxpeyzumnyuzbqia2hlg67p22re/SABCS+abstract1.pdf.
1 Joensuu H, Kellokumpu-Lehtinen PL, Bono P, Alanko T, Kataja V, Asola R, Utriainen T, Kokko R, Hemminki A, Tarkkanen M, Turpeenniemi-Hujanen T, Jyrkkiö S, Flander M, Helle L, Ingalsuo S, Johansson K, Jääskeläinen AS, Pajunen M, Rauhala M, Kaleva-Kerola J, Salminen T, Leinonen M, Elomaa I, Isola J, for the FinHer Study Investigators: Adjuvant docetaxel or vinorelbine with or without trastuzumab for breast cancer. N Engl J Med 2006;354:809-820.

12 Piccart-Gebhart MJ, Procter M, Leyland-Jones B, Goldhirsch A, Untch M, Smith I, Gianni L, Baselga J, Bell R, Jackisch C, Cameron D, Dowsett M, Barrios $\mathrm{CH}$, Steger G, Huang CS, Andersson M, Inbar M, Lichinitser M, Láng I, Nitz U, Iwata H, Thomssen C, Lohrisch C, Suter TM, Rüschoff J, Sütö T, Greatorex V, Ward C, Straehle C, McFadden E, Dolci S, Gelber RD, for the Herceptin Adjuvant(HERA) Trial Study Team: Trastuzumab after adjuvant chemotherapy in her2-positive breast cancer. N Engl J Med 2005;353:1659-1672.

13 Protocol of Herceptin adjuvant with reduced exposure. http://www.e-cancer.fr/v1/index.php?lang=1\& vers $=1$ \&lang $=2$ \&vers $=1$. 